\title{
Somatostatin analogues effectiveness in non-functioning pituitary adenomas in comparison to acromegaly
}

\author{
Jolanta Kunert-Radek ${ }^{1}$, Natalia Zawada ${ }^{1}$,Marek Pawlikowski ${ }^{2}$, \\ Hanna Pisarek ${ }^{3}$, Maciej Radek ${ }^{4}$
}

'Department of Clinical Endocrinology, ${ }^{2}$ Department of Immunoendocrinology, ${ }^{3}$ Department of Neuroendocrinology, ${ }^{4}$ Department of Neurosurgery \& Peripheral Nerves Surgery Medical University of Lodz

\section{Introduction}

Somatostatin analogues (SSA) have been used for many years in the treatment of somatotropinomas and thyreotropinomas. Recently some publications focus on the use of these drugs in the therapy of clinically non-functioning pituitary adenomas (NFPA):

in recurrent tumors after incomplete surgical resections of invasive adenomas

- in primary adenomas in a case of patient's disagreement for operation or in situation of some medical contraindications for surgery. Aim of the study:

The assessment of SSA treatment in patients with NFPA in comparison to patients with acromegaly.

\section{Material \& methods}

62 patients treated in The Department of Clinical Endocrinology of Medical University of Lodz: Acromegaly: 40 patients (28 women and 12 men, aged 29-73), 24 patients with primary adenomas, 16 - with secondary tumors, treated with SSA from 6 months to 10 years;

10 patients with additional dopamine agonist therapy

NFPA: 22 patients ( 13 women and 9 men, aged 24-77 lat), 5 patients with primary adenomas,

17 - with secondary tumors (8 patients - operated once, 9 patients - after several operations), treated with SSA from 6 months to 10 years; 13 patients with additional dopamine agonist therapy

Somatostatin receptor scintigraphy was performed in every patient with NFPA. High density of SSTR2 in the tumor - a mandatory condition for SSA therapy introduction (Fig. 1). SSTR subtypes were also assessed in immunohistochemistry of surgically removed tumor tissue (Fig. 2).

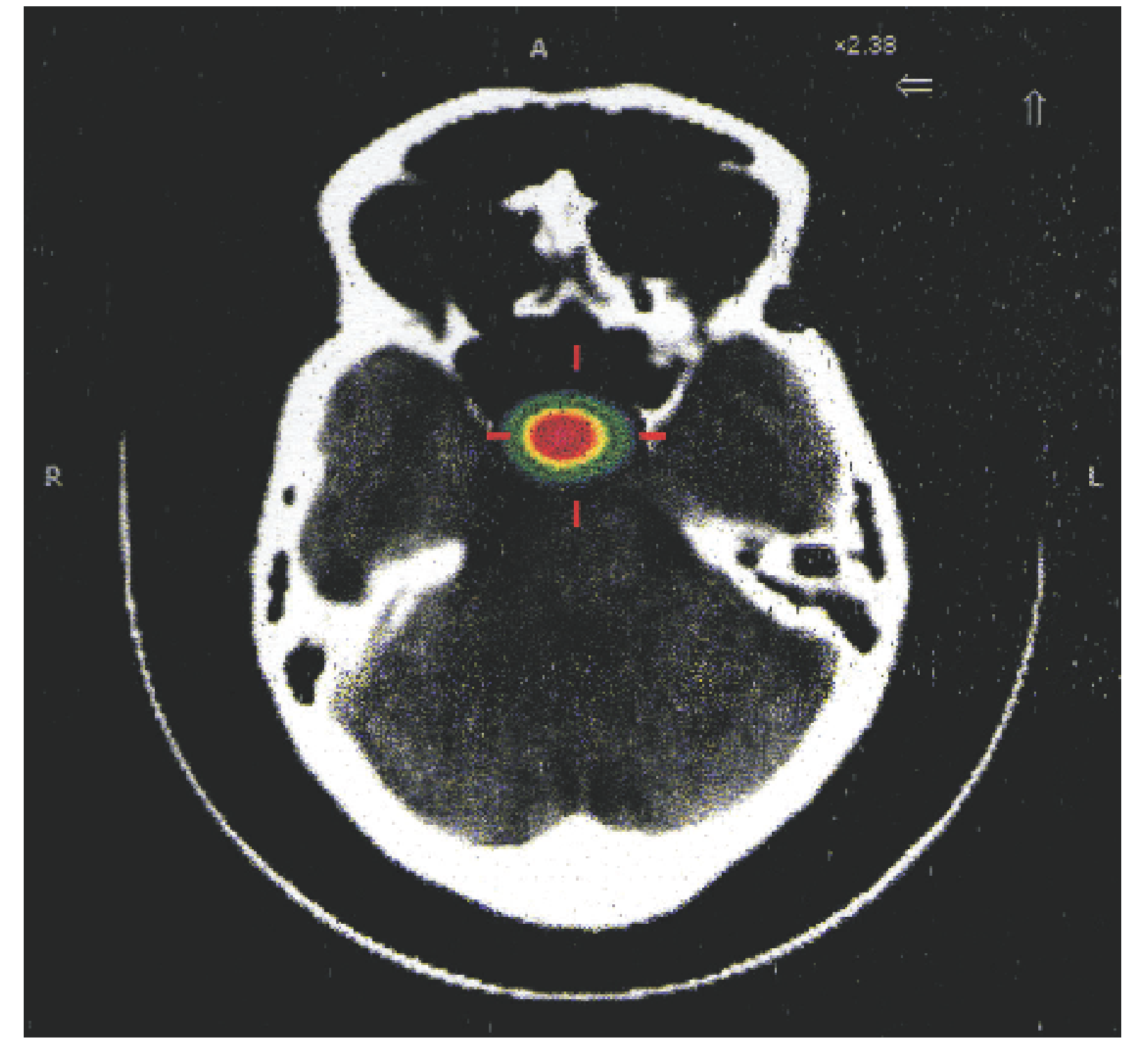

Fig. 1. Somatostatin receptor scintigraphy (SSTR 2) in patient with NFPA

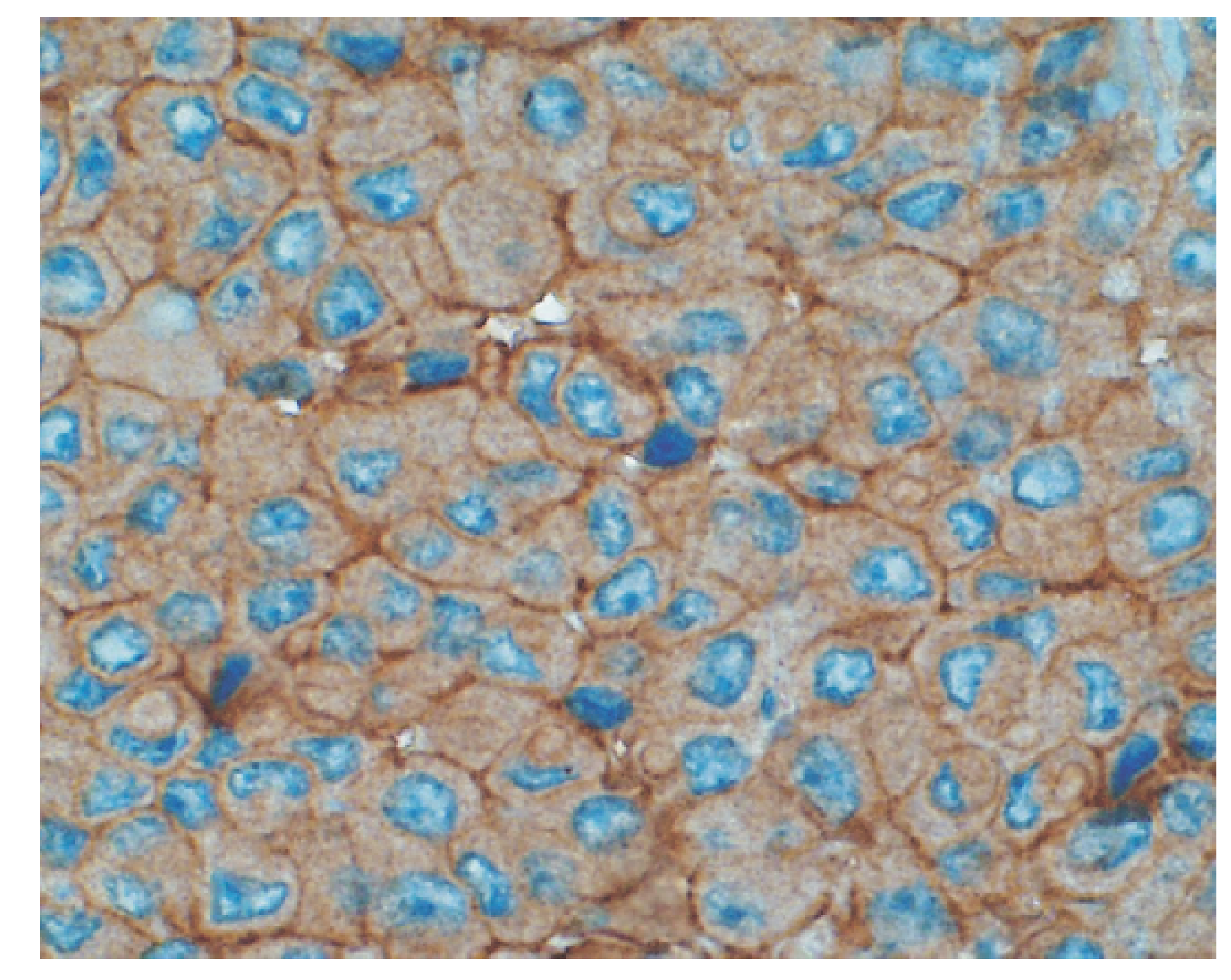

Fig. 2. Immunohistochemistry of SSTR 2A (membrane localization) in NFPA

\begin{tabular}{|c|c|c|}
\hline Assessed parameters & Acromegaly & NFPA \\
\hline HGH \& IGF-1 & $\begin{array}{c}\downarrow 95 \% \\
\text { (50\% normalization) } \\
\end{array}$ & - \\
\hline$\downarrow$ tumor size $\geq 20 \%$ & $\begin{array}{l}40 \% \\
\text { (81.25\% primary tumors) } \\
\end{array}$ & $\begin{array}{c}9 \% \\
\text { (only in recurrent tumors) } \\
\end{array}$ \\
\hline tumor size stabilization & $52.5 \%$ & $68 \%$ \\
\hline $\begin{array}{l}\uparrow_{\text {tumor size with indication }} \\
\text { to neurosurgical treatment }\end{array}$ & $7.5 \%$ & $23 \%$ \\
\hline side effects & $\begin{array}{c}7.5 \% \text { symptomatic } \\
\text { cholelithiasis } \rightarrow \text { cholecystectomy }\end{array}$ & - \\
\hline improvement of quality of life & $>95 \%$ & about $40 \%$ \\
\hline
\end{tabular}

\section{Conclusions:}

1. Somatostatin analogues are effective in the treatment of acromegaly, also in cases of primary tumors.

2. The effectiveness of somatostatin analogues therapy in patients with NFPA is lower in comparison to acromegalic ones.

3. In most cases of NFPA pharmacotherapy with somatostatin analogues lead to stabilization of tumor size and can be an alternative for next neurosurgeries of recurrent invasive adenomas. 